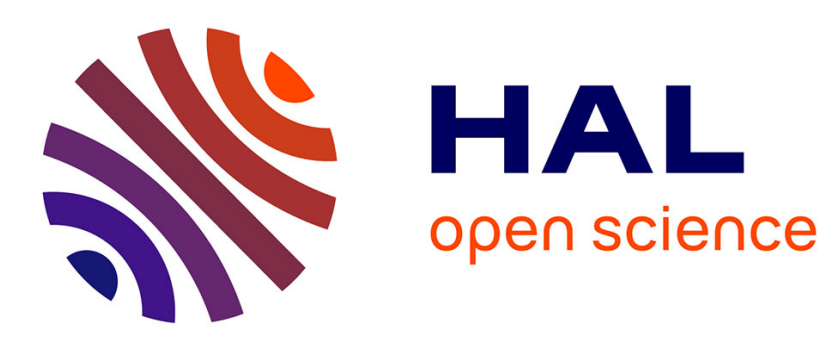

\title{
The Coupled Multi-scale Downscaling Climate System : a decision-making tool for developing countries
}

\author{
Florian Lemarié, Marc Honnorat
}

\section{To cite this version:}

Florian Lemarié, Marc Honnorat. The Coupled Multi-scale Downscaling Climate System : a decisionmaking tool for developing countries. OCEANS 2010, Sep 2010, Seattle, WA, United States. pp.1-9, 10.1109/OCEANS.2010.5664389 . hal-00661973

\section{HAL Id: hal-00661973 https://hal.science/hal-00661973}

Submitted on 22 Jan 2012

HAL is a multi-disciplinary open access archive for the deposit and dissemination of scientific research documents, whether they are published or not. The documents may come from teaching and research institutions in France or abroad, or from public or private research centers.
L'archive ouverte pluridisciplinaire $\mathbf{H A L}$, est destinée au dépôt et à la diffusion de documents scientifiques de niveau recherche, publiés ou non, émanant des établissements d'enseignement et de recherche français ou étrangers, des laboratoires publics ou privés. 


\title{
The Coupled Multi-scale Downscaling Climate System : a decision-making tool for developing countries
}

\author{
Florian Lemarié and Marc Honnorat
}

\begin{abstract}
The purpose of this paper is to introduce and evaluate a high-resolution (5km) atmospheric downscaling system. The NCEP-NCAR Reanalysis and the NCEP-DOE Reanalysis II are used to drive a 30 years multi-scale simulation. We report in this paper the different steps for the implementation of the downscaling strategy. Our system has been applied to the east coast of South America with a specific emphasis put on Uruguay. We validate the results by carrying out a direct comparison with the available historical in situ observations. We show that our simulation develops a good representation of the seasonal and interannual variability for temperature and winds in the surface layer. The methodology presented here provides a basis for generalizing this approach to future studies especially for regions with a very limited observational network. Moreover we are on the path to include more precise informations about the sea-state by adding a wave model in our downscaling system.
\end{abstract}

Citation : F. Lemarié and Honnorat, M., The coupled multi-scale downscaling climate system : A decision-making tool for developing countries, OCEANS 2010, pp.1-9, 20-23 Sept. 2010

doi: 10.1109/OCEANS.2010.5664389

\section{Introduction}

Assessing the impacts of climatic vagaries and the vulnerability in developing countries requires a high-level of expertise in order to obtain good quality information. This is however only the first step towards the design of long-term solutions for local populations to optimize the coping strategies. For a lot of region all over the world, climate information is either unavailable or extremely sparse. In these regions there is thus currently a strong need not only for a good low-frequency climatology but also for a good depictation of extreme events in terms of occurence and preconditioners. Because those informations are lacking we introduce here a methodology whose objective is to try to cope with this recurrent problem. We have implemented a systematic way to produce at high spatial $(5 \mathrm{~km})$ and temporal (3-hourly) resolutions all the necessary climatic information (e.g. temperature, winds, rainfalls or oceanic waves). Such a fine resolution is absent in IPCQ ${ }^{1}$-type models. Our approach is built around some strong guidelines :

$\overline{1}$ Intergovernmental Panel on Climate Change 
- For some particular regions the local nearshore waves may be of interest because of the possible occurence of wind-driven surge or significant wave growth that can have disastrous effects for coastal regions.

- The areas under consideration have a very limited amount of observations available (developing countries)

- Those areas are mainly coastal regions and/or regions with steep topography

There are mainly two techniques to achieve those goals : the statistical downscaling and the dynamical downscaling (i.e. regional modelling). The statistical downscaling relies on a presupposed statistical relationship, defined empirically, between the large scale dynamics and the local small scale features. Starting from coarse resolution global circulation models the principle is to use the available finer scale informations (e.g. for topography, vegetation, sea surface temperature) and/or observations to build an empirical function mapping the large scales onto the fine scales. The calibration of this kind of function is not an easy task and requires some long-term and reliable observational series of small scales variability. This is the key component for a "good" statistical downscaling, especially when highly nonlinear processes are under investigation. For well instrumented regions statistical downscaling is a viable and very attractive alternative (Murphy, 1999) due to its numerical efficiency. As mentioned earlier, for our particular problem we have only access to a very limited amount of observational data. Because the size of the sample would be hardly considered as "representative", this makes it difficult or even "dangerous" to rely on a statistical approach.

The second possibility called dynamical downscaling is based on the numerical resolution of the atmospheric circulation governing equations (i.e. the fully compressible Euler equations with some possible additional assumptions (Skamarock and Klemp, 2008)). Obviously, this approach is much more technically demanding than the statistical one but is not subject to limitations in case of absence of observational data. The principle is to use data from a general circulation model as lateral boundary conditions (and eventually SSTs) to drive a local high resolution regional domain : this is the so-called 1-way nesting method. It is also possible to complement this method by a feedback of the fine grid onto the coarse grid in order to improve their dynamical consistency (Debreu and Blayo, 2008). As far as the downscaling of oceanic waves is concerned the same remarks apply (Breivik et al., 1999).

Taking into account all the elements and constraints introduced so far we decided to implement a numerical framework for the dynamical downscaling from atmospheric (resp. waves) large scale models to a small scales high resolution local model : we have called this global-to-regional downscaling system the Coupled Multi-scale Downscaling Climate System (CMDCS hereafter). Here the objective is to introduce the various components of this system. This paper is organized as follows. In sections 2 and 3, we will motivate our choice respectively for the dynamical and the physical core of the CMDCS. We will then explain our general strategy to downscale the global information in section 4. Finally in section 5 we show some results of the application of the CMDCS along the Atlantic coast of southern America.

\section{Dynamical kernel}

To fulfill our original goal, the target horizontal resolution is of the order of a few kilometers (typically $5 \mathrm{~km}$ ). Such fine resolution is needed for direct explorations of features associated with small-scale topographic variations and other extreme weather features. This, by itself, prevents the use of an hydrostatic atmospheric model. The hydrostatic balance between vertical pressure gradient and compression due to gravity is only valid when the ratio between the vertical scales and the horizontal scales is much smaller 
than one. This is particularly true for the large scale circulation of the atmosphere explaining why most of the GCMs (Global Circulation Models) are hydrostatic models. However this assumption is no longer acceptable when one wants to accurately resolve the mesoscales.

\subsection{Atmospheric mesoscale model}

A wide number of non-hydrostatic Numerical Weather Prediction (NWP) models have been developped during the recent years : we can mention among others the PSU ${ }^{2} \mathrm{NCAR}^{3}$ Mesoscale Model (MM5), the High Resolution Limited Area Model (Hirlam), the Weather Research and Forecasting model (WRF) or the Coupled Ocean/Atmosphere Mesoscale Prediction System (COAMPS). Our choice will be motivated by the type of computational grid for discretization and the treatment of acoustic modes. Indeed, at mesoscales the kinetic energy (KE) is dominated by the kinetic energy associated with divergent modes (associated to the $k^{-5 / 3}$ slope in the KE spectrum), as opposed to the dominance of the rotational energy at the large scales ( $k^{-3}$ slope) (Hamilton et al., 2008). This leads to the natural choice of a C-grid discretization (in the Arakawa classification), discarding MM5 (B-grid discretization) from the list of our possible choices as well as the WRF-NMM 4 dynamical core (E-grid discretization). Indeed the C-grid is especially accurate to resolve divergent motions. Besides the hydrostatic assumption a second important hypothesis can be made : the anelastic approximation. The anelastic models (like Hirlam or COAMPS) filter the acoutic waves. This filtering amounts to neglect certain compressibility effects and can potentially induce imprecisions in the computation of vertical velocities and the propagation of pressure disturbances. The latter are particularly important for surge modelling. Our choice turns towards a fully-compressible model explicitely resolving the acoustic waves via time-splitting (Skamarock and Klemp, 2008). The ARW 5 dynamical core version 3.2 of the WRF model (Skamarock et al., 2008) is thus the mesoscale atmospheric model used for this study. The equations solved by WRF are the fully-compressible Euler equations. Those equations are relevant to resolve the scales from a few centimeters (cloud scales) to a few hundred kilometers (climate scales). Moreover, from the numerical point of view, all the numerical schemes are perfectly suitable for long-term simulation at high resolution. The order of accuracy of those schemes (e.g. for advection and time stepping) allows for a scale selective dissipation "pushing" the dropoff in the KE spectrum to very small scales. WRF has, among other things, already shown a good capability to reproduce fine scales wind-sst coupling (Song et al., 2009) and the local orographic effects (Galewsky, 2004). Those two aspects are of peculiar importance for our target applications. More generally recent studies showed that the model performed well to simulate the regional climate at high resolution, e.g. over Japan (Kusaka et al., 2009). Note that a few recent studies showed little benefits of using WRF instead of MM5. However those studies were carried out at relatively coarse horizontal resolution $(25 \mathrm{~km})$. It is expected that the benefits of WRF become more apparent when going to higher and higher resolution due to its more accurate numerical methods.

\footnotetext{
2 Pennsylvania State University

3 National Center for Atmospheric Research

4 Nonhydrostatic Mesoscale Model

5 Advanced Research WRF
} 


\subsection{Wave model}

Our downscaling system also includes a wave model : the WAVE-WATCH III $^{\mathrm{TM}}$ modelling framework in its version 3.14 (Tolman, 2009b). This model has been developed by the NOAA ${ }^{6}$, NCEP. WAVEWATCH III ${ }^{\mathrm{TM}}$ solves the random phase spectral action density balance equations for wavenumber-direction spectra. A very interesting feature of version 3.14, besides the possibility to do 2-way nesting (Tolman, 2009a), is the "mosaic" approach : we can define a grid with variable spatial resolution, thus enabling the possibility to refine the resolution where it is needed (typically near the coastline) and to coarsen it offshore. This feature makes it possible to increase the resolution locally while keeping a "reasonable" computational cost. This is especially interesting when one is dealing with coastlines with a very complex geometry, like for example in Rio de La Plata (Fig. 3).

\section{Physical parameterizations}

The main factors for variance at mesoscales are essentially associated to terrain, land-use, water-land boundaries and clouds. When the resolution of the model is not sufficient we need to add physical parameterizations in order to accurately take into account those sources of variance. For the Planetary Boundary Layer (PBL) mainly two theoretical formulations are available : the TKE (Turbulent Kinetic Energy) based schemes or the nonlocal K-profile schemes. For the present study we chose to use the YSU (Yonsei university) K-profile scheme implemented in WRF. Its physical basement is inherited from the Troen and Mahrt (1986) scheme. This scheme has been extensively and successfully used for long-term climatological simulations, e.g. in the framework of the CCSM 7 (Community Climate System Model). Moreover during the last few years the scheme has been further tuned and improved thanks to large-eddy simulations.

The Rapid Radiative Transfer Model (RRTM) is used to parameterize radiative processes. Over land, the Noah Land Surface Model (LSM) provides the surface fluxes. This 4-layer scheme accounts for the vegetation processes. Depending on the region of interest and on the target resolution the choices for the microphysics and the cumulus convection must be rethought. For example when running the model with a horizontal resolution of 5km (or finer), we don't use any cumulus parameterization anymore. Indeed the convective motions are assumed to be explicitely resolved in this situation. This is necessary to do it to avoid any double counting when the model tries to parameterize processes that are explicitely resolved.

Note that in theory we can expect that the fact that we are running WRF at high-resolution enables us to minimize the sensitivity of the solution to the choice of the parameterization schemes. Indeed when the resolution of the model tends to zero the effect of the parameterizations should also be less because more and more processes usually parameterized are resolved. However, as we will see in the next section, our downscaling strategy is based on an embedding of grids with different horizontal resolutions. Thus, the previous remark about the effect of the parameterizations only applies for the finer grid of our hierarchy.

\footnotetext{
6 National Oceanic and Atmospheric Administration
}

7 http://www.cesm.ucar.edu/ 


\section{Downscaling strategy}

As mentioned in section 1, we intend to implement a dynamical downscaling technique. In this section we motivate and we describe our methodology. For this study the low frequency variability is provided by the coarse resolution $(250 \mathrm{~km}) \mathrm{NCEP}^{8} / \mathrm{NCAR}$ global reanalysis data (Kanamitsu et al., 2002). Those data are available every 6 hours from 1948 to 1979 for NCEP R1 product and from 1979 to present for the NCEP R2 product. In order to get a smooth and consistent transition from the large scales down to the small scales we define a hierarchy of embedded WRF grids (Fig. 1) with a horizontal resolution typically ranging from $75 \mathrm{~km}$ (for $G_{0}$ ) to $5 \mathrm{~km}$ (for $G_{2}$ ). At each increase of resolution we add more accurate informations about the sea-state, the vegetation, or the topography. Consequently, the representation of the processes strongly forced by topography, such as orographic precipitation, improves at increased resolution.

The two main difficulties associated to this approach are : how to handle the interaction between the external NCEP data and the WRF coarser grid ? as well as the interaction between the WRF grids ?

For our downscaling strategy we define a coarse resolution grid $G_{0}$. This coarse resolution grid is forced at its boundaries by the NCEP reanalysis. However in order to avoid any significant drift in the long-term tendency we also add a relaxation towards the external data. This nudging is done in a spectral way (Miguez-Macho et al., 2004) meaning that the low-frequency (in time and space) characteristics of our simulations remain perfectly consistent with the NCEP reanalysis. This strategy presents several advantages. First, this constrains the synoptic scales of $G_{0}$ to follow the reanalysis while allowing the model to develop its intrinsic small-scale dynamics. Moreover, this reduces the sensitivity of the solution to the size and the position of the WRF domains, as shown in (Miguez-Macho et al., 2004). Indeed without this kind of nudging the large-scale variability can be lost if the WRF domain is too large and thus weakly constrained by its boundaries. It is obvious that this approach is viable only if we assume that the scales in the NCEP reanalysis are good enough, which is our underlying basic assumption. As described in Fig. 1 the $G_{0}$ solution is used to provide boundary conditions to the finer grids $G_{1}$ and hence $G_{2}$ (online nesting technique). Moreover this nesting can be done in a 2-way manner to increase the consistency between the different grid levels. This allows to minimize the reflections at the boundaries (Harris and Durran, 2010). When one uses the wave model the necessary surface fields (10 meters winds essentially) are interpolated from $G_{2}$. A feedback from the wave field onto the drag coefficient computed by WRF could be added up. This additional feature is however still under investigation and requires further theoretical work.

Note that no data assimilation technique are used in our modelling framework. The first obvious reason is that very few observations are available for our regions of interest (developing countries). Even with a sufficient amount of observations the implementation of data assimilation would increase significantly the complexity as well as the computational cost of our downscaling system.

\section{Application to the Atlantic coast of southern South America}

We have applied the CMDCS along the Atlantic coast of southern America (over Uruguay) in the framework of the CLIMSAT's initiative driven by the United Nations Development Program (UNDP). The geographical position of the three WRF grids is shown in Fig. 2. Each grid has 31 vertical levels that are configured to enhance resolution near the surface. We ran a simulation for 30 years, from January 1970 to December 1999 with an output every 3 hours. The surface boundary conditions for the SST (Sea

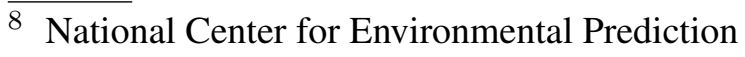




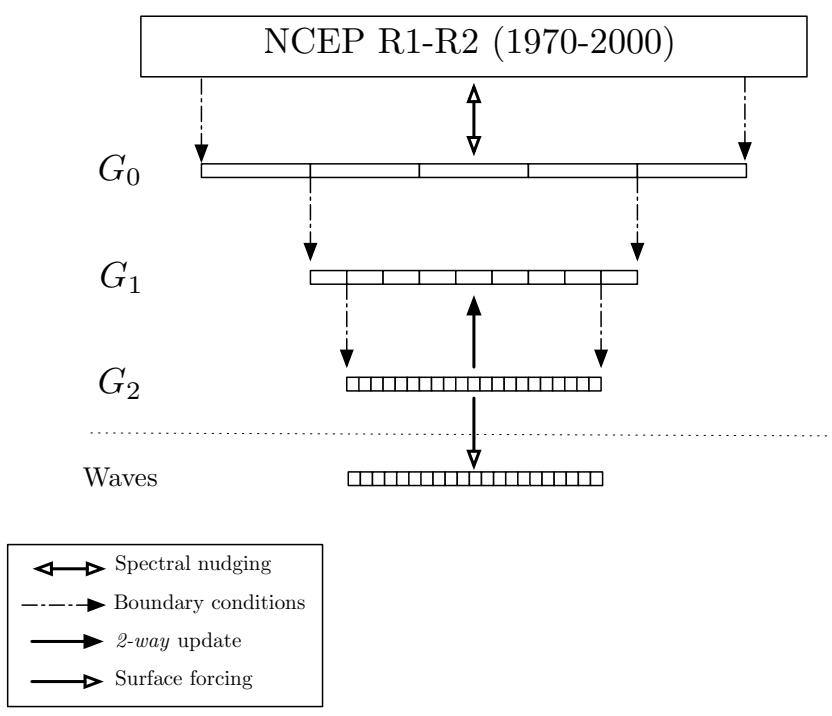

Fig. 1. Schematic view of the downscaling strategy. $G_{0}$ is spectrally nudged to the reanalysis data (NCEP R1-R2) and provides boundary conditions for $G_{1} . G_{1}$ provides boundary conditions to $G_{2}$. When the wave model is used the required surface fields are interpolated from $G_{2}$. The development of a feedback from the wave field onto $G_{2}$ is currently under investigation.

\section{Grid hierarchy}

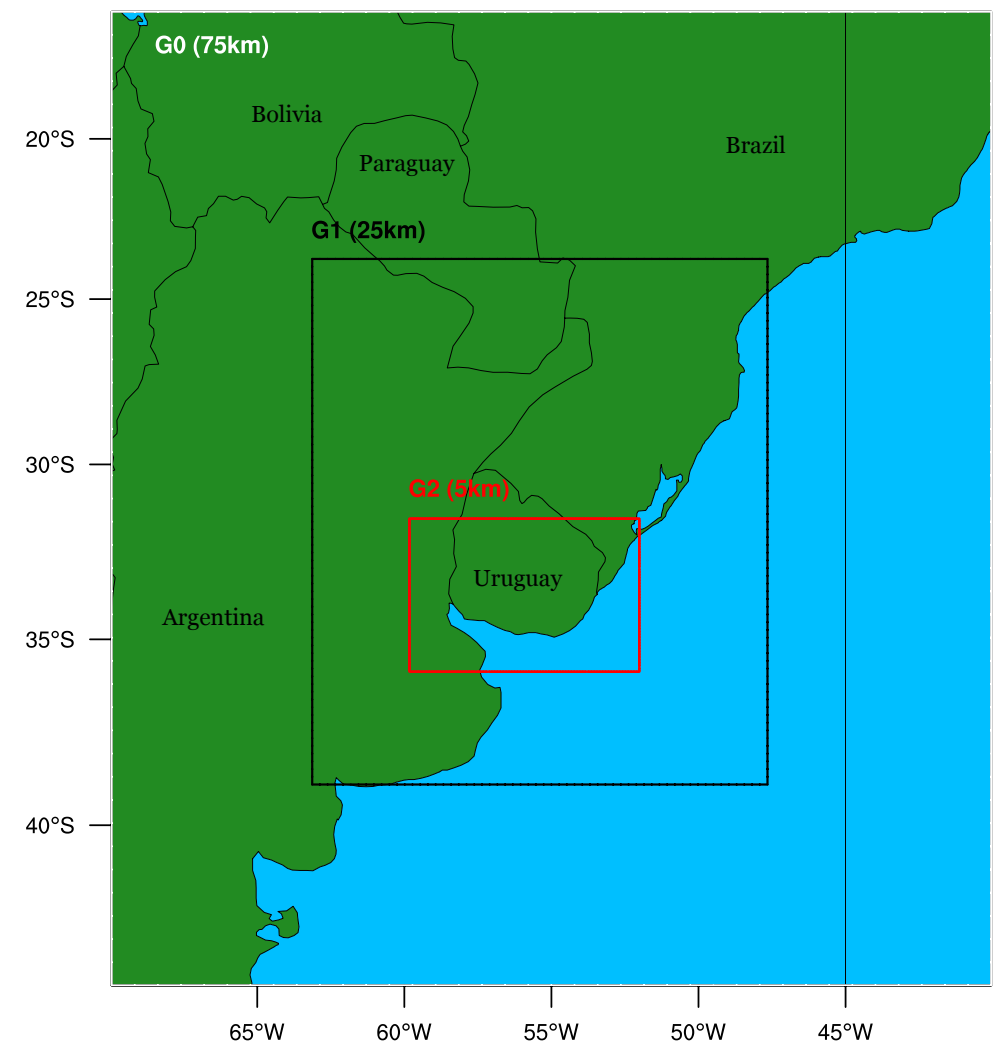

Fig. 2. Grid hierarchy centered over Uruguay. 
Surface Temperature) are interpolated from the Simple Ocean Data Assimilation (SODA) reanalysis 9 The SST is an important factor in the region for its potential feedback on precipitation anomalies Diaz et al. (1998). We used the parameterization schemes mentioned in section 3 as well as the Single-Moment 3-class (WSM3) microphysics, and the Betts-Miller-Janjic scheme for cumulus convection (for grids $G_{0}$ and $G_{1}$ only).

Note that the reader must be aware of the fact that a numerical model corresponds to an imperfect representation of the nature and must be interpreted more in a statistical way. One of the major difficulty for the development of numerical models comes notably from the fundamentally multiscale behaviour (in space and time) of the phenomena one is trying to represent. That's the reason why we must rely on physical submodel to parameterize the subgrid scales. Those subgrid scale parameterizations are by construction imperfect because they try to represent turbulent motions that are partially unknown and fundamentally random motions.

For these reasons the best way to validate a climatological simulation is first to look at the interannual and seasonal variability. We used the surface temperature from the Global Historical Climatology Network $\left(\mathrm{GHCN}^{10}\right.$ ) at six given stations : Punta del Este, Rocha, Melo, Colonia, Mercedes and Treinta y tres (Fig. 3 ) for the period 1980-1990. The differences for monthly means between WRF and the observations for each stations are plotted in Fig. 4. In general we see that WRF tends to simulate temperatures warmer than observations during the summer (this may be due to biases in the simulated cloud cover). But the overall agreement is good : the relative error never exceeds $15 \%$ and is generally around 3-9\%. The interannual variability is well represented by the model with relatively colder winter for 1983 and 1988 for example. Our comparison was carried out with the observations taken from stations located at the air-sea boundary (e.g Punta del Este, Colonia) or close to topographic features (e.g melo, rocha). The model behaved pretty well in both cases.

In Fig. 5 we compare a 18 years seasonal climatology of WRF 10 meter winds (for the period 19801998) with a climatology computed from the new NCEP Climate Forecast System Reanalysis (CFSR) Saha (2010). This new product is a 30 years reanalysis with a resolution of 38 kilometers. We show that the seasonal variability between WRF and CFSR is consistent : weak winds during fall and winter, moderate winds during spring and summer. From those plots we clearly see why it is necessary to use a high-resolution model for the kind of study we are doing. WRF is able to accurately resolve the air-sea transition (especially in spring and summer when the winds blow from sea to land). The advantage of using a $5 \mathrm{~km}$ grid is also obvious when one is looking at the Patos Lagoon or at Rio de La Plata. Overall the WRF winds contain more small scales features essentially due to a more accurate representation of the topography.

\section{Conclusion}

We have integrated the WRF and the WW3 models into a single system that produces high-resolution multi-purpose climate statistics. We have shown the ability of this system to produce climatologies in complex terrain and in coastal regions. Moreover our modelling framework has been especially designed to be easily portable to any region of the world. This preliminary evaluation has shown that the WRF model is a viable and potentially useful tool for regional climate modelling. The next step in our validation

\footnotetext{
9 http://www.atmos.umd.edu/ ocean/

${ }^{10} \mathrm{http}: / /$ www.ncdc.noaa.gov/oa/climate/ghen-monthly/
} 


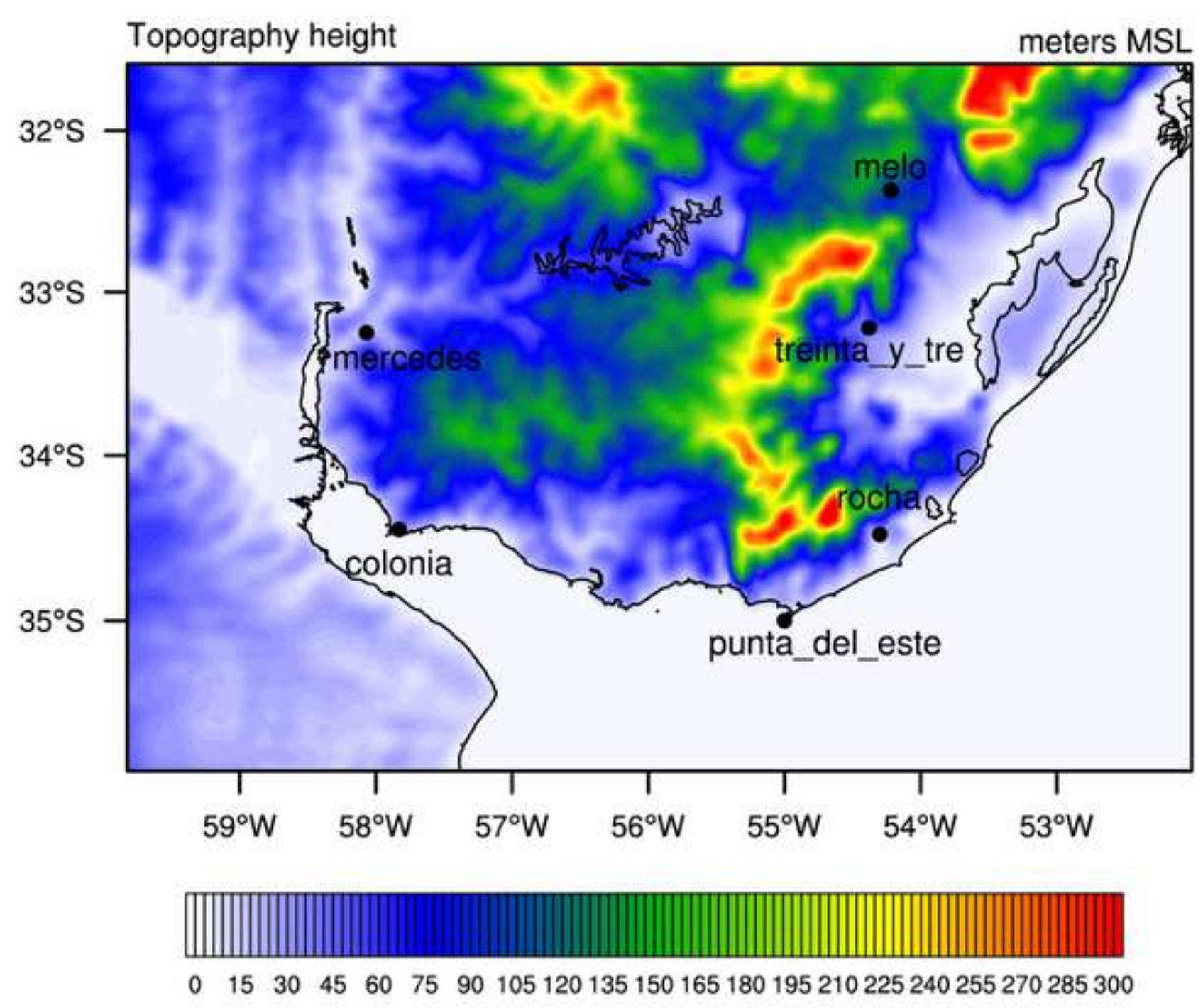

Fig. 3. Topography $[m]$ of the high resolution domain $\left(G_{2}\right)$ and location of the stations.

work is now to look at statistics of extreme events and at the sub-monthly variability.

\section{Acknowledgment}

This work was supported by the CLIMSAT's initiative funded by the United Nations Development Program (UNDP). The computations were made at the Regional High Performance Computer System based on the CAPARMOR supercomputer located at Ifremer's Brest Centre. The NCEP R2 reanalysis was produced with the support of the US National Weather Service and of PCMDI (US Dept. of Energy). The SODA Model monthly ocean reanalysis data for oceanographic climate variables were processed by CSIRO Division of Marine and Atmospheric Research. 

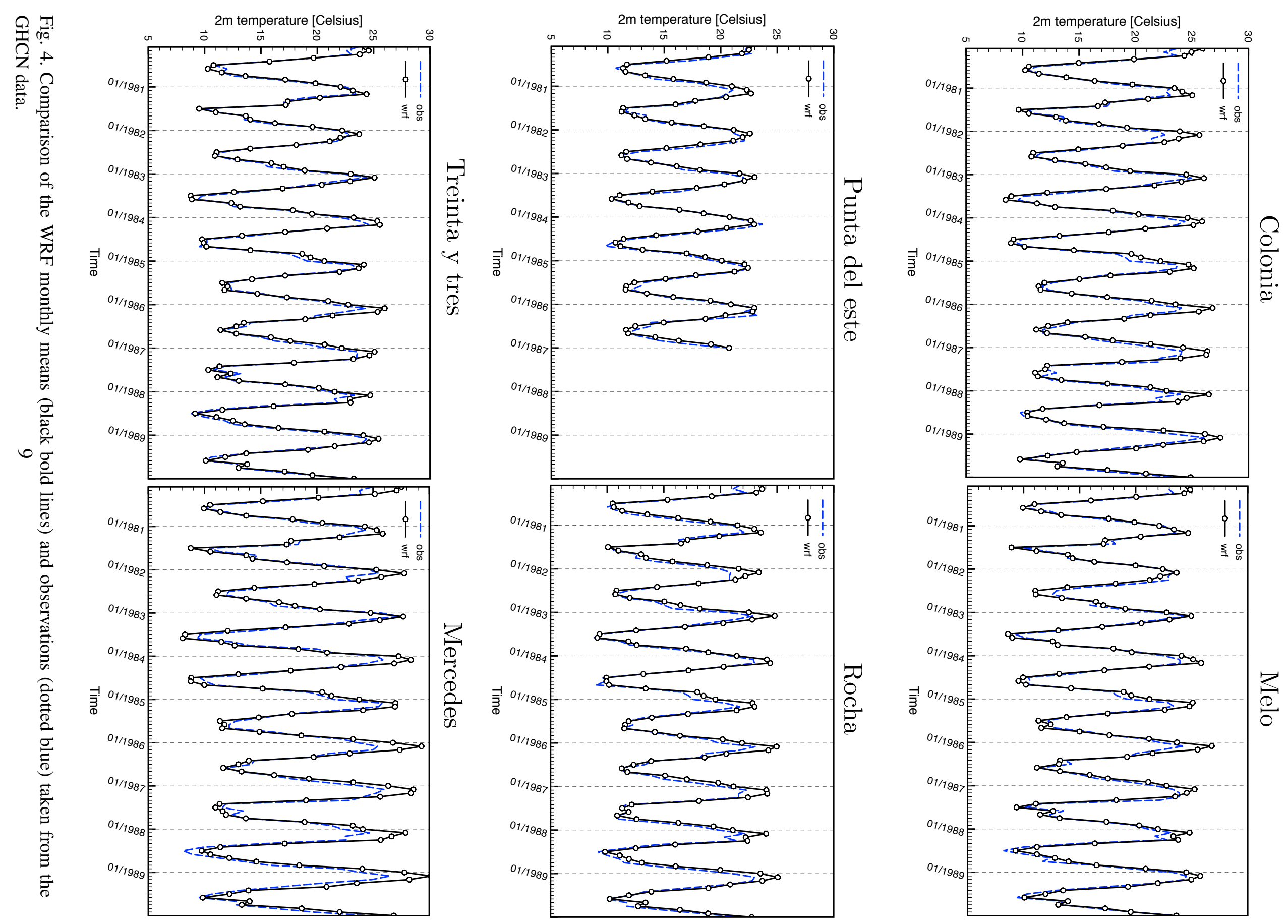


\section{NCEP CFSR}

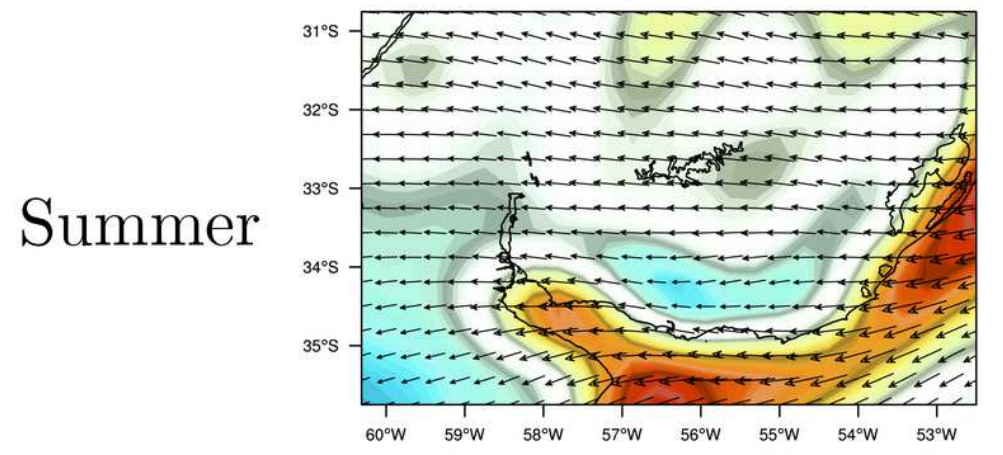

Fall

Winter

Spring
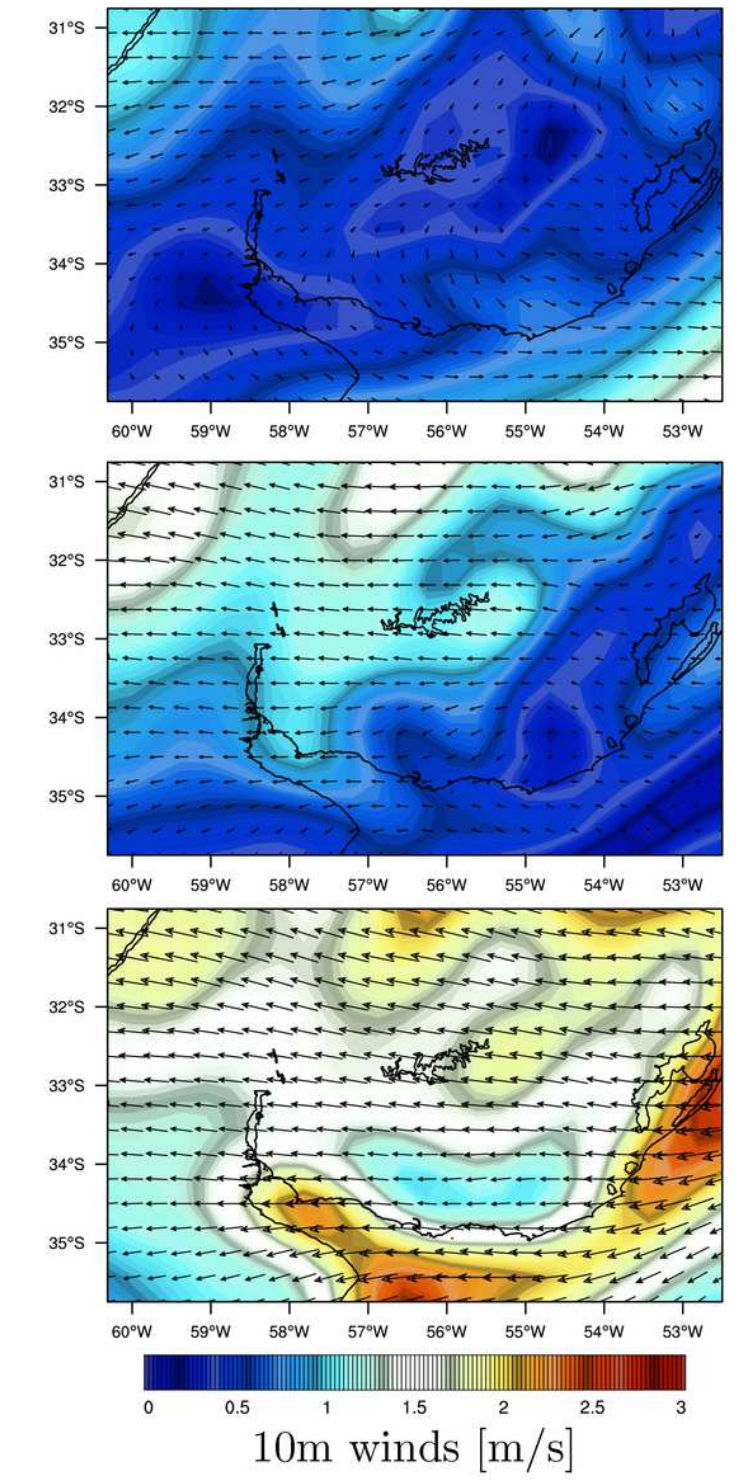

WRF
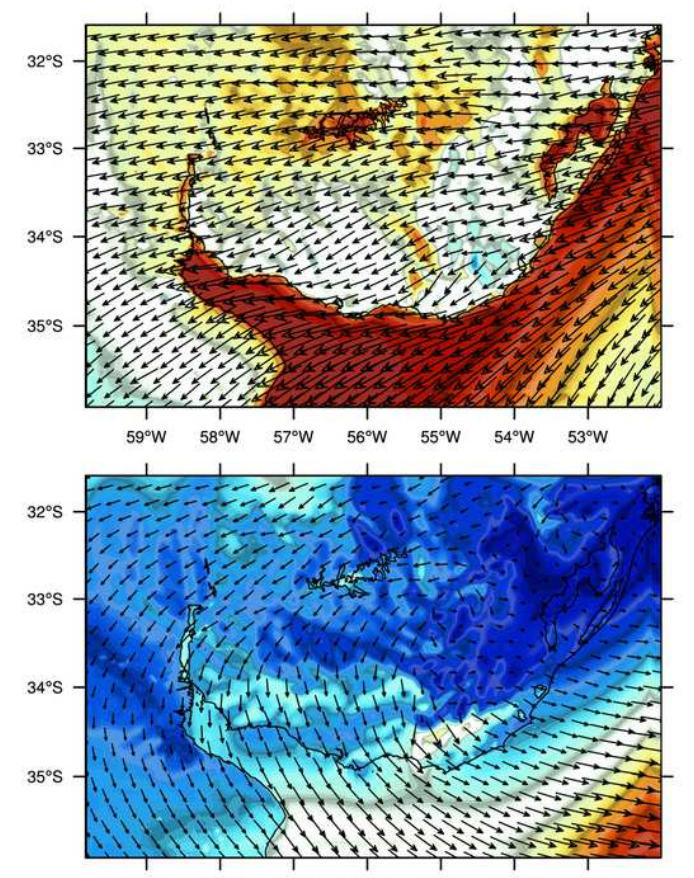

$59^{\circ} \mathrm{W} \quad 58^{\circ} \mathrm{W} \quad 57^{\circ} \mathrm{W} \quad 56^{\circ} \mathrm{W} \quad 55^{\circ} \mathrm{W} \quad 54^{\circ} \mathrm{W} \quad 53^{\circ} \mathrm{W}$
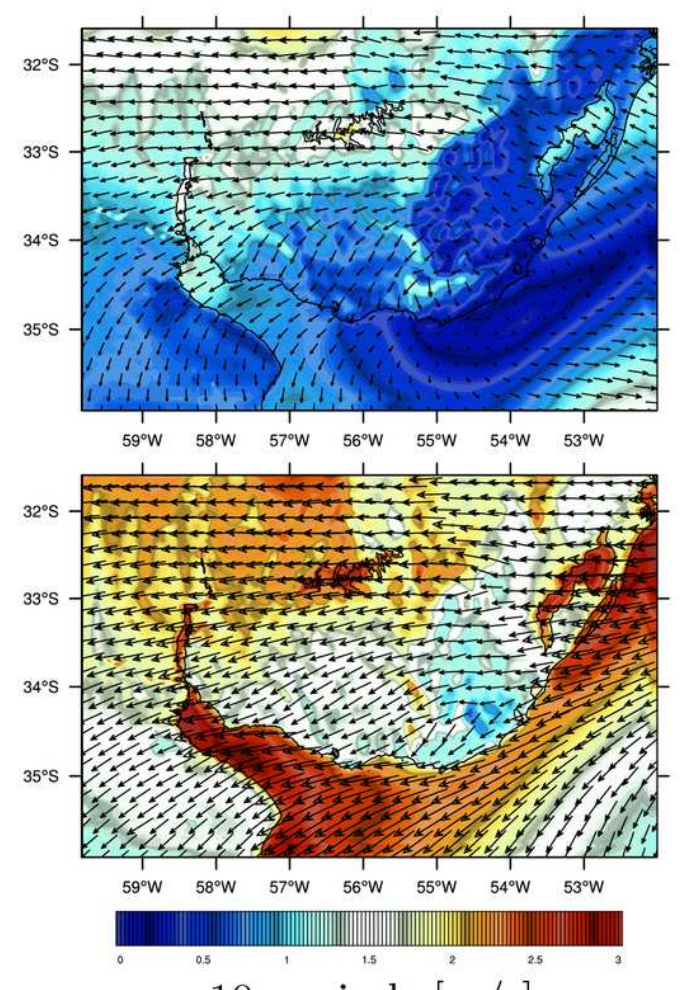

Fig. 5. Comparison of the 10 meter winds for the WRF seasonal means from 1980 to 1998 (right panel) and the NCEP CFSR seasonal means over the same periods (left panel). 


\section{References}

Breivik, O., Gusdal, Y., Furevik, B.R., Aarnes, O.J., Reistad, M., 1999. Nearshore wave forecasting and hindcasting by dynamical and statistical downscaling. Journal of Climate .

Debreu, L., Blayo, E., 2008. Two way embedding methods: a review. Ocean Dynamics .

Diaz, A.F., Studzinski, C.D., Mechoso, C.R., 1998. Relationships between precipitation anomalies in uruguay and southern brazil and sea surface temperature in the pacific and atlantic oceans. J. Climate .

Galewsky, J., 2004. Nonlinear influences of topography on orographic precipitation. Geological Society of America, Denver Annual Meeting .

Hamilton, K., Takahashi, Y.O., Ohfuchi, W., 2008. Mesoscale spectrum of atmospheric motions investigated in a very fine resolution global general circulation model. Journal of Geophysical Research

Harris, L.M., Durran, D.R., 2010. On the relative performance of one-way and two-way grid nesting. Monthly Weather Review .

Kanamitsu, M., Ebisuzaki, W., Woollen, J., Yang, S.K., Hnilo, J.J., Fiorino, M., Potter, G.L., 2002. Ncepdoe amip-ii reanalysis (r-2). Bull. Amer. Meteor. Soc. .

Kusaka, H., Chen, F., Tewari, M., Duda, M., Dudhia, J., Miya, Y., Akimoto, Y., 2009. Performance of the wrf model as a high-resolution climate model : Model intercomparison study. Proceedings of the 7th international Conference on Urban Climate .

Miguez-Macho, G., Stenchikov, G.L., Robock, A., 2004. Spectral nudging to eliminate the effects of domain position and geometry in regional climate model simulations. Journal of Geophysical Research

Murphy, J., 1999. An evaluation of statistical and dynamical techniques for downscaling local climate. Journal of Climate .

Saha, Suranjana, e.a., 2010. The ncep climate forecast system reanalysis. Bull. Amer. Meteor. Soc. .

Skamarock, W.C., Klemp, J.B., 2008. A time-split nonhydrostatic atmospheric model for weather research and forecasting applications. Journal of Computational Physics 227, 3465-3485.

Skamarock, W.C., Klemp, J.B., Dudhia, J., Gill, D.O., Barker, D.M., Duda, M.G., Huang, X.Y., Wang, W., Powers, J.G., 2008. A description of the advanced research wrf version 3. NCAR Tech Notes-475+STR

Song, Q., Chelton, D.B., Esbensen, S.K., Thum, N., O’Neill, L.W., 2009. Coupling between sea-surface temperature and and low-level winds in mesoscale numerical models. Journal of Climate .

Tolman, H.L., 2009a. Development of a multi-grid version of wavewatch iii. NOAA / NWS / NCEP / MMAB Technical Note 256, 88 pp.+ Appendices .

Tolman, H.L., 2009b. User manual and system documentation of wavewatch iii version 3.14. NOAA / NWS / NCEP / MMAB Technical Note 276, 194 pp.+ Appendices .

Troen, I.B., Mahrt, L., 1986. A simple model of the atmospheric boundary layer; sensitivity to surface evaporation. Boundary Layer Meteorol. . 